\title{
Integrated Product and Process Development of Clutch Friction Material Using Quality Function Deployment Processes
}

\author{
Zhengfeng Yan ${ }^{1, a}$, Guangping $\mathrm{Tu}^{2, \mathrm{~b},{ }^{*}}$ and Jiajun $\mathrm{He}^{3, \mathrm{c}}$ \\ ${ }^{1}$ School of Mechanical Engineering, Hefei University of Technology, China, 230009 \\ 2 Getrag group, Nanchang, Jiangxi, China, 330013 \\ ${ }^{3}$ School of Mechanical Engineering, University of Jilin, China, 130012 \\ *Corresponding author, ${ }^{\mathrm{a}}$ zf.yan@hfut.edu.cn, ${ }^{\mathrm{b}}$ tuguangping@126.com, ${ }^{\mathrm{c}}$ jiajun.he@jlu.edu.cn
}

\begin{abstract}
Using an improved quality function deployment (QFD) process, an integrated product and process development method was proposed for the clutch friction material, one key part of driveline. The importance ratings of customer requirements for the clutch friction material was calculated and synthesized through the reasonable selection of respondents and the method to determine customer requirements based on importance of rough analytic hierarchy process (AHP) in QFD. Using improved QFD decomposition model, the quality house between customer requirements and part features, process matrix and the key process control sample table were established. The method can be widely used in the development of other key parts.
\end{abstract}

\section{Introduction}

As it's expected for the design team to achieve product function design, part feature design, selection of processing method, manufacturability design, choice of technical scheme and many other objectives in the whole process of product development, system engineering method is required to help materialize integrated product and process development (IPPD). IPPD is a system engineering method in the context from product concept across production and on-site support activities, and an important characteristic of IPPD is close integration of product in manufacturing process [1,2]. Quality function deployment (QFD), however, is a rounded scientific methodology for systematic quality development based on business practical experiences from product design and manufacturing activities. In the development course of QFD theory, integrated QFD mode (Yoji Akao Mode), ASI (American Supplier Institute) four-stage mode and GOAL/QPC mode (Growth Opportunity Alliance of Lawrence, Inc.) have been evolved. More specific fourstage process is invented by J.R.Hauser, D.Clausing et al[3], which starts with customer requirement and then goes through four stages, i.e. product planning stage, part configuration stage, process design stage and production control stage.

In the face of proliferating product specialization, many small and medium-sized enterprises (SMEs) focus on production of a special category of key part for an assembly, such as clutch fiction material (CFM). CFM, as a key part of driveline, is a part material for activation of transmission function on the principle of friction effect. Friction of clutch facing is a complex problem, which, in view of its highly sensitive property, is affected by such factors as test force, temperature, rotating speed, medium and the like[4], together with notable impact of process. Due to technical research of assembly manufacturers in integrated product process of key parts is far from indepth, traditional ASI four-stage mode is no longer effective in changing customer requirement to part feature. Here CFM is chosen as the subject for related research, with which analysis is conducted with the impact of product property and reliability life-cycle by many procedures, including material preparation, mixing, coating, winding, hot pressing, thermal stabilization and mechanical machining, and an improved quality function deployment process is suggested to establish integrated product process design method for CFM, which pinpoints customer requirement through reasonable selection of research objects and research method, in the aim to integrate abundant expertise of part manufacturer and customer requirement in a more effective manner. Effectual integration of QFD and IPPD technology will bring innovative change in product development, and it is advisable to apply this method in design and manufacturing processes of the manufacturers of other key parts, so as to realize effective and systematic upgrading of product development quality.

\footnotetext{
a Corresponding author: tuguangping@126.com
} 


\section{Integrated Product and Process Development Methodology}

\subsection{Clutch friction material product and process analysis}

Automotive clutch is a part for disconnecting and transmitting power between the engine and the driveline, Fig. 1 is a schematic diagram of vehicle driveline.

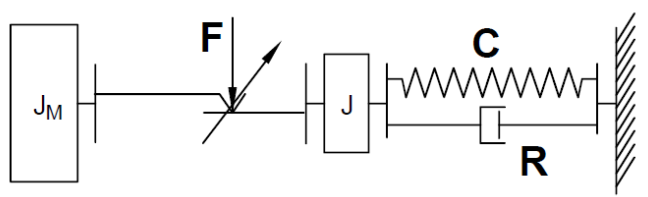

Fig.1 Simple model of vehicle driveline

Clutch torque calculation is shown as equation 1 .

$$
M_{(\varphi)}=2 * \mathrm{~F} * \mu_{(\varphi)} * r
$$

F-clamping force;

$\mu_{(\varphi)}$-friction coefficient;

$r$-effective radius.

Kinetic formula is shown as equation 2.

$$
J * \varphi+R * \varphi+C * \varphi=M_{(\varphi)}=2 * \mathrm{~F} * \mu_{(\varphi)} * r
$$

\section{$\mathrm{J}, \mathrm{R}, \mathrm{C}$-the moments of inertia; \\ $\varphi$-angular displacement. [5]}

CFM is a key part in this type of driveline, and its main functions are to transmit kinetic force through friction to enable safe and reliable operation of the vehicle. CFM is a widely used key material.

Essential requirements for clutch facing: stable coefficient, perfect comfort, good wear performance, withstanding high temperature and minimal thermal deformation; high strength, withstand impact, high speed stability; no adhesion; long lifetime and cost effective, and so on. Moreover, friction material should be environmental friendly and harmless to human health.

Production process of friction facing is illustrated in Fig. 2. [6]

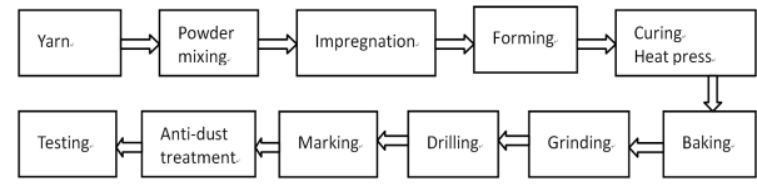

Fig. 2 Production process flow diagram of CFM

2.2 Integrated product and process development of CFM using improved quality function deployment process

Base on the characteristics of key parts manufacturers, an improved quality function deployment process, with following particular steps:

Step 1: Select reasonable research respondents, identify customer requirement and importance rating;

Step 2: Carry out IPPD;

Step 3: Build the house of quality for customer requirement and part feature;

Step 4: Construct process matrix, establish process control parameters;

Step 5: Establish key process production control table.

\section{Determining the importance rating of customer requirement}

In this article, Delphi Method is employed in designing questionnaire and identifying customer requirement. With this method, hierarchy of customer requirement is derived from affinity diagram, tree diagram and cluster analysis on the basis of original customer requirement on clutch friction material obtained. In classifying customer requirements, the study took eight basic quality factors, namely, property, feature, reliability, durability, serviceability, consistency, aesthetics and perceived quality, as the criteria for the completeness of customer requirement data by which the design team will be guided in the product development process (PDP)[7], and 14 customer requirements are identified as the key in the design and development of clutch friction material. Moreover, hierarchical chart of customer requirements is derived from cluster analysis and affinity diagram based upon actual situation of CFM, as shown in Fig. 3. 


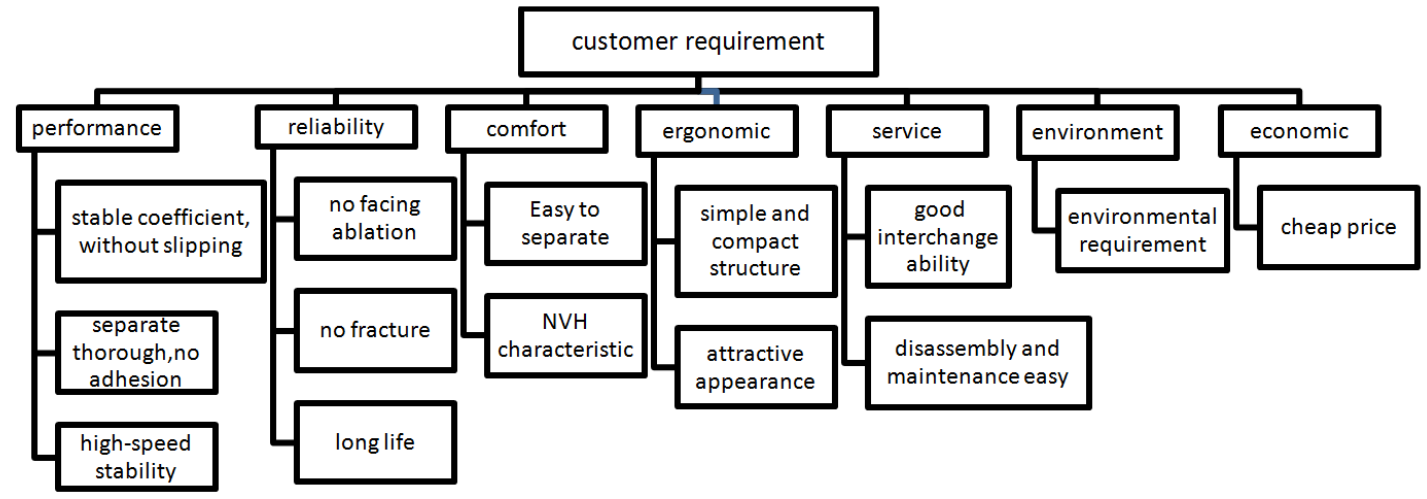

Fig.3 the hierarchy of customer requirements

Base on expert assessment method, five types of "experts" ("car manufacturer's driveline professionals", "professionals in vehicle clutch sector", "CFM product designers \& testers", "CFM process designer", "vehicle clutch servicemen") are selected to participate in the judgment of importance rating of customer requirement, and one AHP matrix is constructed in terms of judgment result for each group, five AHP judgment results are obtained, with five AHP pairwise comparison matrices derived.
To determine the importance rating of customer requirements, many scholars have adopted different processing methods $[8,9]$. Base on determination of importance rating of customer requirements with rough analytic hierarchy process of QFD[10], importance rating of customer requirements in each hierarchy is calculated, and importance rating of CFM customer requirement is derived, as shown in Fig. 4.

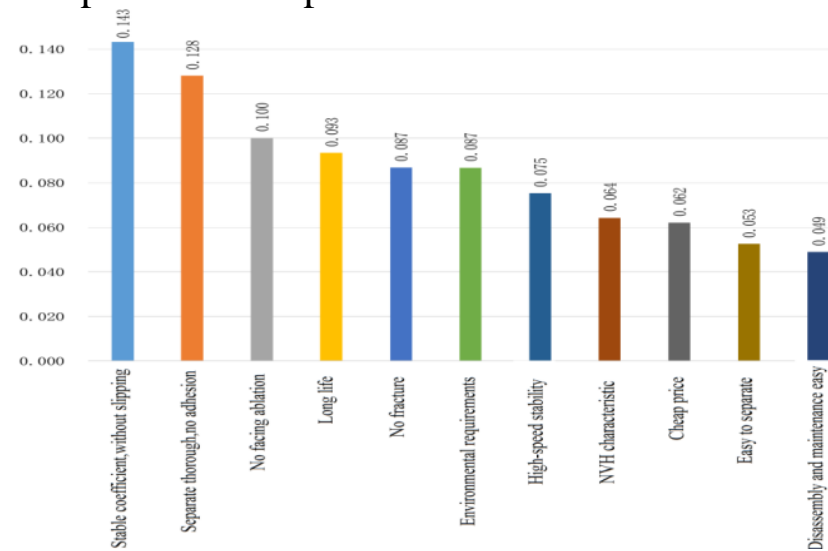

Fig.4 the importance ranking of customer requirements for clutch friction material

\section{Integrated Product and Process Development of Clutch Friction Material}

As nearly each use/each loading condition or each customer requires different CFM, and due to the property and life-cycle of CFM necessitate selection of different product material and process, we need to weigh and conduct integrated material and process design based on material performance. For development of new CFM product, we should start with describing from the aspects of friction coefficient, wear, judder, burst speed, rupture, interchangeability and cost, then carry out integrated product and process design according to the requirements, determine material and processing technology, and obtain better performance advantage by screening method[11], as shown in Fig. 5.

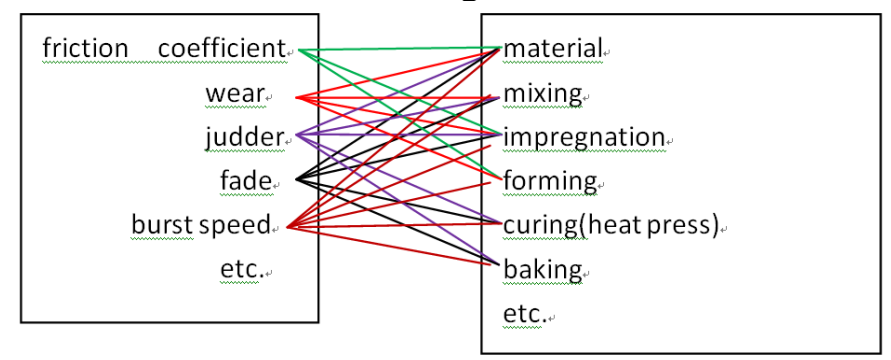

Fig. 5 Relational graph of performance of CFM versus composition material and key Process

\section{Build House of Quality for Customer Requirements \& Part Features}

a Corresponding author: tuguangping@126.com 
With the house of quality, customer requirements are converted to part features, and the same type of products in the market is assessed from the perspective of the customer, from which target value of CFM characteristics is determined.

A matrix of relation between customer requirements and part features is constructed, where $(0, \bigcirc$ and $\Delta$ represent the intensity of correlation between customer requirements and each part feature, respectively, standing for Strong, Intermediate and Weak relations.
Two leading transnational enterprises are selected for the assessment of competitiveness by means of expert scoring, digits $1 \sim 5$ are used to represent the degree of customer satisfaction to a given customer requirement, the higher the score, the better the customer satisfaction.With autocorrelation matrix and matrix of relation of customer requirements versus part features determined, assessment of competitiveness is conducted, and the house of quality is derived by adding the contents in various parts in corresponding areas of the diagram, as shown in Fig. 6.

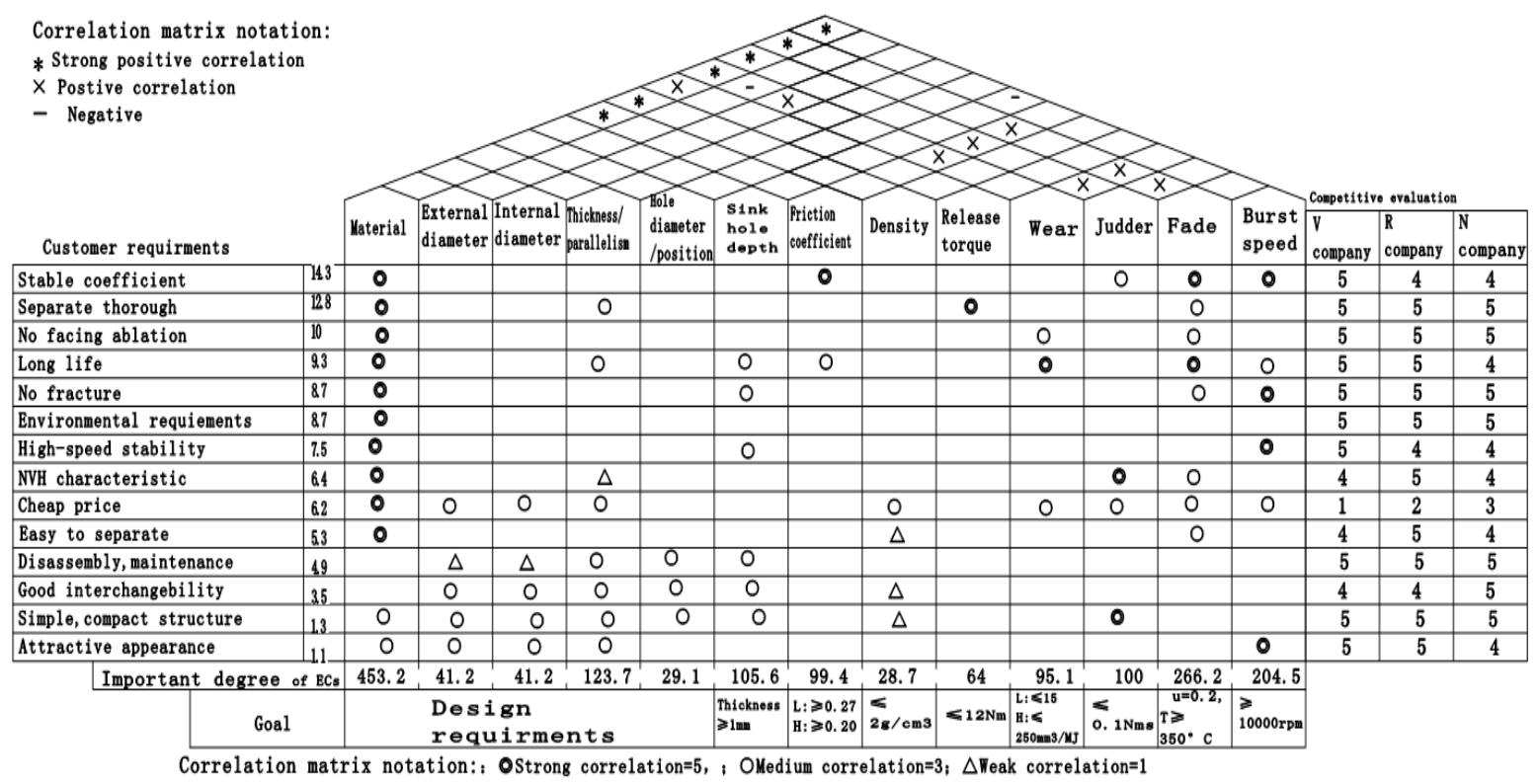

Fig. 6 Quality house of customer requirements versus part features

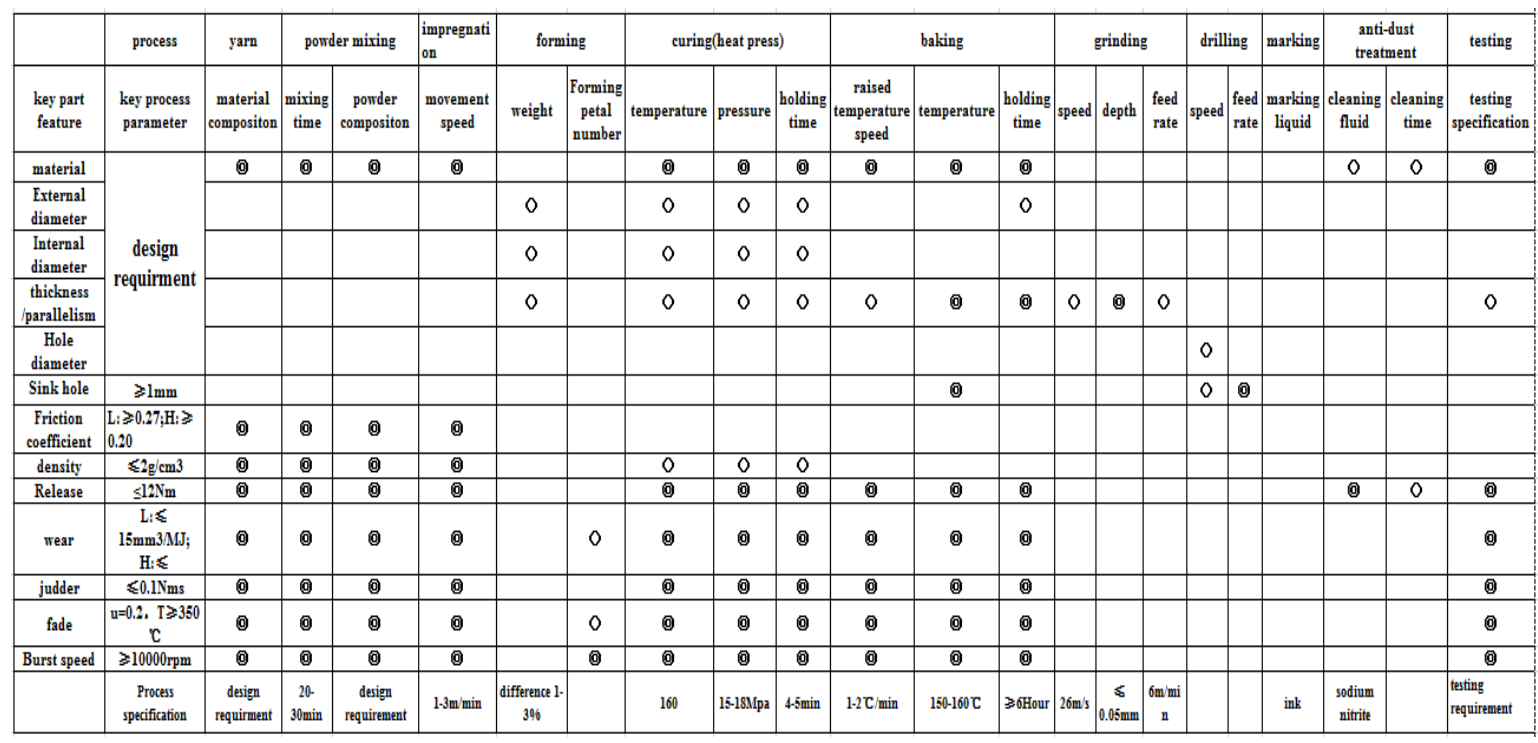

Fig. 7 Process matrix 


\section{Establishing Key Process Production Control Table}

The output of the house of process design quality is manufacturing process characteristic requirements; in order to meet these requirements, corresponding production requirements should be established and production method be designed to establish the house of QFD production control quality. The input of the house of production control quality is manufacturing process characteristic, while the output is production requirements and control method.

Because each enterprise is unique in terms of equipment condition, production size, technical strength etc, certain difference exists between the structures of the house of production control .Table 1 shows control method determined by a given enterprise in terms of its own production situation.

Table 1 Sample CFM key process production control table (partial)

\begin{tabular}{|c|c|c|c|c|c|}
\hline Process & $\begin{array}{l}\text { Process } \\
\text { parameter }\end{array}$ & $\begin{array}{l}\text { Production } \\
\text { requirements }\end{array}$ & $\begin{array}{l}\text { Control } \\
\text { method }\end{array}$ & Inspection approaches & Evaluation \\
\hline \multirow{2}{*}{$\begin{array}{l}\text { Powder } \\
\text { mixing }\end{array}$} & Mixing time & $20-30 \mathrm{~min}$ & PLC & Time recorder & Control chart \\
\hline & $\begin{array}{l}\text { powder } \\
\text { composition }\end{array}$ & $\begin{array}{l}\text { Design } \\
\text { requirement }\end{array}$ & $\begin{array}{l}\text { Automat } \\
\text { ic } \\
\text { machine }\end{array}$ & composition analyzer & $\begin{array}{l}\text { Sampling } \\
\text { check }\end{array}$ \\
\hline Impregnation & $\begin{array}{l}\text { Movement } \\
\text { speed }\end{array}$ & $1-3 \mathrm{~m} / \mathrm{min}$ & PLC & Speed sensor & Calibration \\
\hline \multirow[t]{2}{*}{ Forming } & weight & Difference $1-3 \%$ & $\begin{array}{l}\mathrm{NC} \\
\text { machine }\end{array}$ & Electronic scale & $\begin{array}{l}\text { Static process } \\
\text { analysis }\end{array}$ \\
\hline & $\begin{array}{l}\text { Forming petal } \\
\text { number }\end{array}$ & $3-5$ & $\begin{array}{l}\text { Winded } \\
\text { mould }\end{array}$ & Naked eye & $\begin{array}{l}\text { Sampling } \\
\text { check }\end{array}$ \\
\hline \multirow{3}{*}{$\begin{array}{l}\text { Curing(heat } \\
\text { press) }\end{array}$} & Temperature & $160^{\circ} \mathrm{C}$ & PLC & Temperature controller & Calibration \\
\hline & Pressure & 15-18Mpa & PLC & Pressure sensor & Calibration \\
\hline & Holding time & $4-5 \mathrm{~min}$ & PLC & Time recorder & Control chart \\
\hline \multirow[t]{3}{*}{ Baking } & $\begin{array}{l}\text { Temperature } \\
\text { raised speed }\end{array}$ & $1-2^{\circ} \mathrm{C} / \mathrm{min}$ & PLC & $\begin{array}{l}\text { Temperature } \\
\text { controller/time recorder }\end{array}$ & Calibration \\
\hline & Temperature & $150-160^{\circ} \mathrm{C}$ & PLC & Temperature controller & Calibration \\
\hline & Holding time & $\geq 6$ Hour & PLC & Time recorder & Control chart \\
\hline
\end{tabular}

\section{Conclusion}

From what has discussed above all, we can draw the conclusions:

( 1 ) The study, by incorporating IPPD technology, calls in CFM IPPD method using improved QFD process, to determine customer requirements from reasonable selection of research objects and the methodology, furthermore, rough analytic hierarchy process is determined from QFD importance rating of customer requirement, so as to calculate compound basic importance rating of customer requirement for clutch friction material.

(2) Starting from customer requirement, and using improved QFD decomposition model, customer requirement is developed in part feature stage, process design stage and production control stage in sequence. From construction of the house of quality for customer requirements and part features, CFM part features are determined. Moreover, corresponding process control parameters are established based on process matrix, and finally, sample key process production control table of clutch friction material is established.

\section{References}

1. Dwivedi S.,Green J. The systems engineering approach to an IPPD implementation [J], International Journal of Computer Applications in Technology,2001,15.

2. John M.Usher,Utpal Roy,Hamid R.Parsaei.Integrated product and process development[M].John Wiley \& Sons, Inc.

3. John $\mathrm{R}$ Hauser,Don Clausing.The house of quality [J],Harvard Business Review, 1988.5-6

4. Shian.Xu,Fachao.Jiang.Automotive clutch [M]. Qinghua university press,2005

a Corresponding author: tuguangping@126.com 
5. Schaeffler Friction Products GmbH.Our testing philosophy for clutch facings [M].Shanghai technical seminar.2010.5

6. Ronghua.Sen,Lin He.Friction material and products production technology [M].Beijing university press. 2010

7. Edward B.Magrab.Integrated product and process design and development-the product realization process [M].Taylor \& Francis Group,2009.73-110

8. Li Yanlai,Tang Jiafu,Yao Jianming.Mehtod of determining the importance ratings of customer requirements' improvements for house of quality.Chinese journal of mechanical engineering,2007,Vol.43(11)

9. Han $\mathrm{C} \mathrm{H}, \mathrm{Kim} \mathrm{J}$ K,Choi S H.Prioritizing engineering characteristics in quality Function deployment with incomplete information: a linear partial ordering approach $[\mathrm{J}]$. International journal of production economics, 2004,91(3).

10. X.T.Wang,W.Xiong, Rough AHP approach for determining the importance ratings of customer requirements in QFD [J]. Computer Integrated Manufacturing Systems, 2010, 16(4)

11. George E. Dieter,Linda C.Schmidt.Engineering Design [M],Fourth Edition.The McGraw-Hill Companies, Inc,2009 